\title{
First report of rheumatoid arthritis and secondary Sjögren's syndrome complicated with heart failure
}

\author{
Shuai $\mathrm{Hao}^{1}$
}

${ }^{1}$ The First Affiliated Hospital of China Medical University

May 28, 2021

\begin{abstract}
A 70-year-old female patient with Rheumatoid arthritis (RA) and secondary Sjögren's syndrome (SS) didn't use long-term hormone and rheumatic immune drugs for treatment, had hyponatremia and chloremia, lacked outdoor exercise, and ultimately led to heart failure.
\end{abstract}

\section{Hosted file}

First report of rheumatoid arthritis and secondary $\mathrm{Sj} \backslash$ selectlanguage\{ngerman\}ögren \selectlanguage\{engli available at https://authorea.com/users/339352/articles/523902-first-report-of-rheumatoidarthritis-and-secondary-sj\%C3\%B6gren-s-syndrome-complicated-with-heart-failure

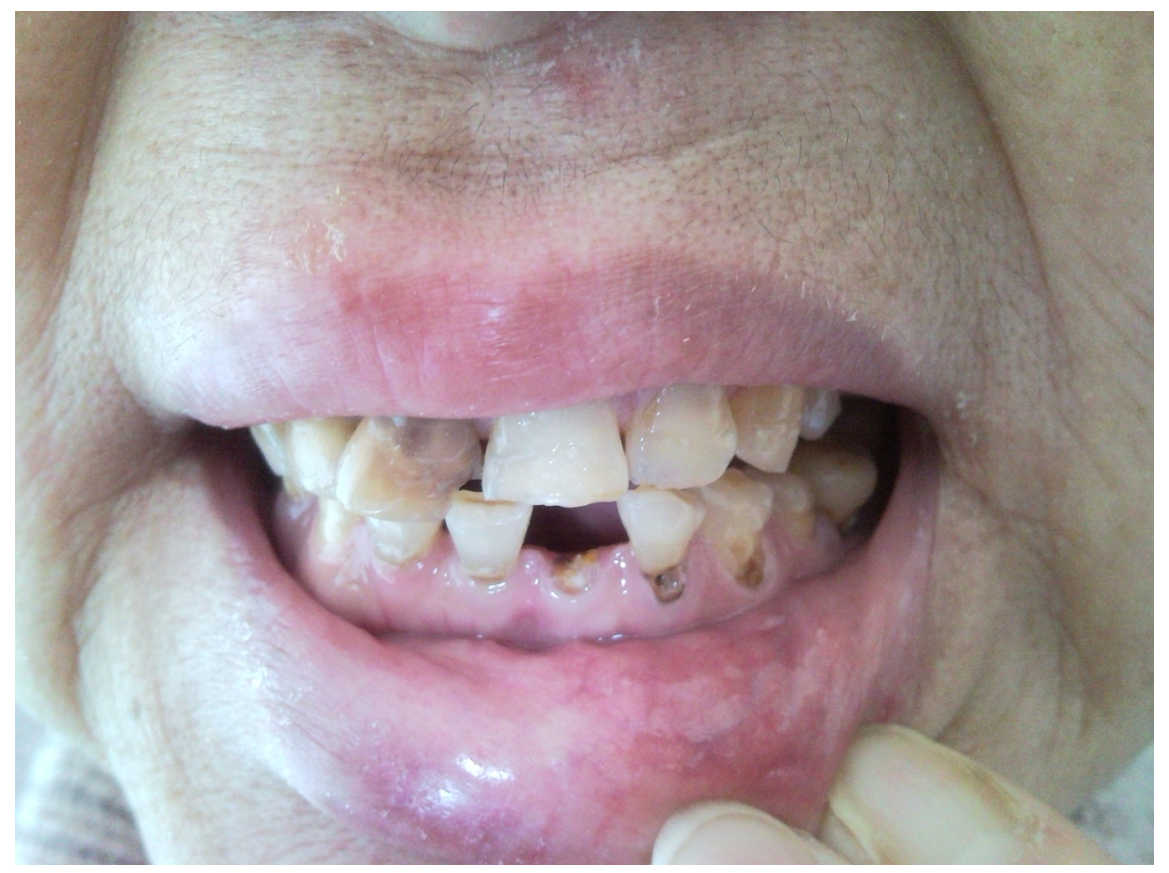




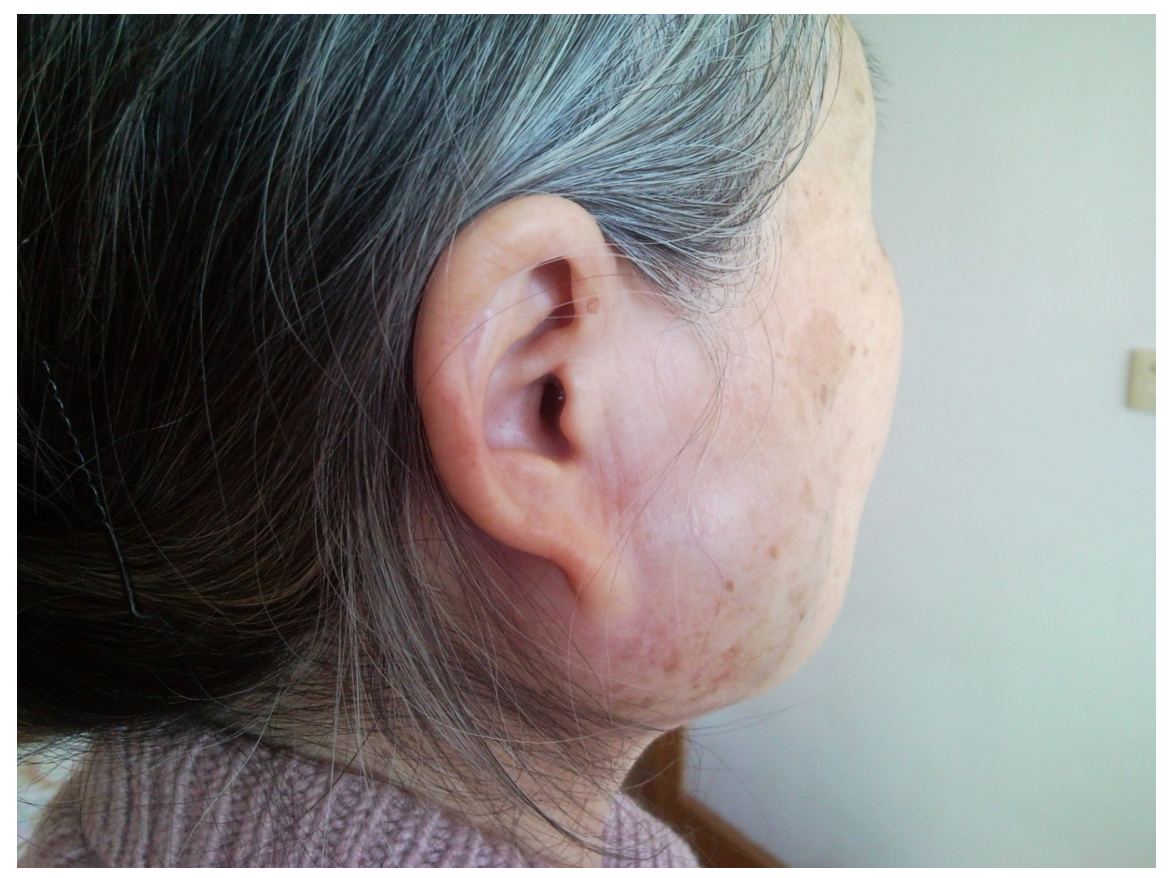

